\title{
Side-chain chiral centers of amino acid and helical screw handedness of its peptides
}

\author{
Masakazu Tanaka, ${ }^{\dagger}{ }^{\dagger}$ Kosuke Anan, ${ }^{\dagger}$ Yosuke Demizu, ${ }^{\dagger}$ Masaaki Kurihara, ${ }^{\ddagger}$ Mitsunobu Doi, ${ }^{\S}$ and \\ Hiroshi Suemune ${ }^{\dagger}$ \\ † Graduate School of Pharmaceutical Sciences, Kyushu University, Fukuoka 812-8582, Japan; \\ ¥ Division of Organic Chemistry, National Institute of Health Sciences, Tokyo 158-8501, Japan; \\ $\S$ Osaka University of Pharmaceutical Sciences, Osaka 569-1094, Japan
}

\section{Supporting Information (J. Am. Chem. Soc.)}

Synthetic scheme of homopeptides

Experimental Section

Fig. S1. Infrared (IR) spectra of Boc-[(R,R)-Ab $\left.{ }_{5,6}=\mathrm{c}\right]_{\mathrm{n}}-\mathrm{OEt}(\mathrm{n}=1,2,3,6,9)$

Fig. S2. ${ }^{1} \mathrm{H}$ NMR experiments by adding radical TEMPO or DMSO to the $\mathrm{CDCl}_{3}$ solution of hexapeptide $\mathbf{1 1}$ and $\mathbf{1 3}$

Fig. S3. The ROESY ${ }^{1} \mathrm{H}$ NMR spectrum of hexapeptide (11)

Fig. S4. The ROESY ${ }^{1} \mathrm{H}$ NMR spectrum of nonapeptide (12)

Fig. S5. CD spectra of 11, 12, and 13

Molecular-mechanics calculation of hexapeptide $\mathbf{1 1}$

Fig. S6. Superimposition of the conformation determined by X-ray analysis and of the calculated minimum-energy conformation

Table S1. Selected torsion angles of $\mathbf{1 1}$ determined by the X-ray crystallographic analysis · S20 
Synthetic scheme of homopeptides: Boc- $\left[(R, R)-\mathrm{Ab}_{5,6}=\mathrm{c}\right]_{\mathrm{n}}-\mathrm{OEt}$

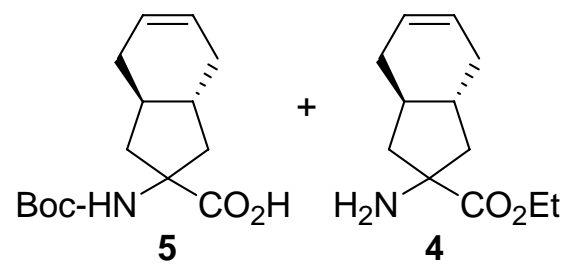<smiles>CCOC(=O)C1(CC)CCCCC1NC(=O)C1(NC(=O)OCc2ccccc2)CC2CC=CCC2C1</smiles>

Boc- $\left[(R, R)-\mathrm{Ab}_{5,6}=\mathrm{C}\right]_{2}-\mathrm{OEt}$

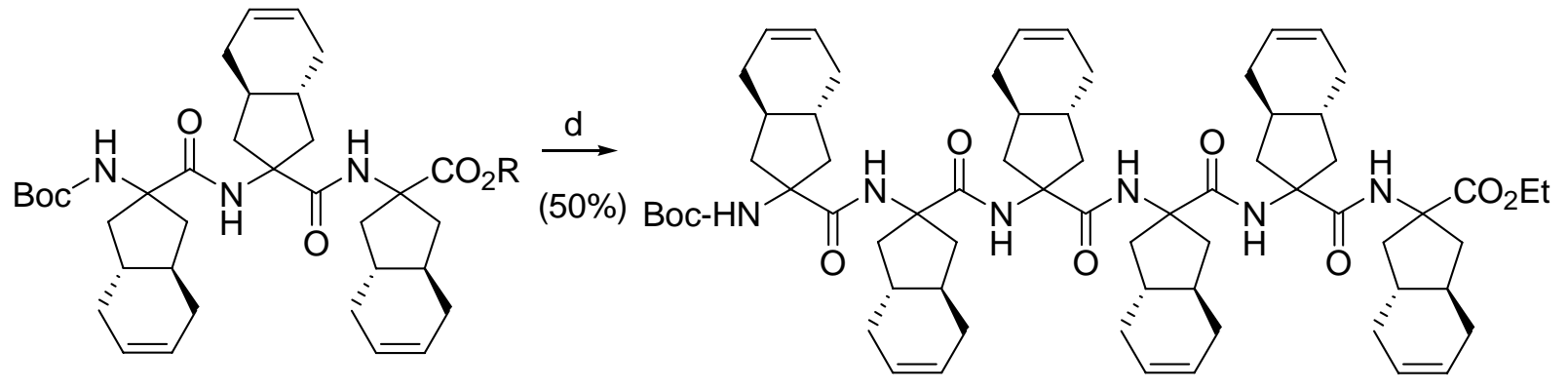

10: $\mathrm{R}=\mathrm{Et}$

Boc- $\left[(R, R)-\mathrm{Ab}_{5,6}=\mathrm{C}\right]_{3}-\mathrm{OH}: \mathrm{R}=\mathrm{H} \longleftarrow(>99 \%)$

11: $\mathrm{Boc}-\left[(R, R)-\mathrm{Ab}_{5,6}=\mathrm{C}\right]_{6}-\mathrm{OEt}$

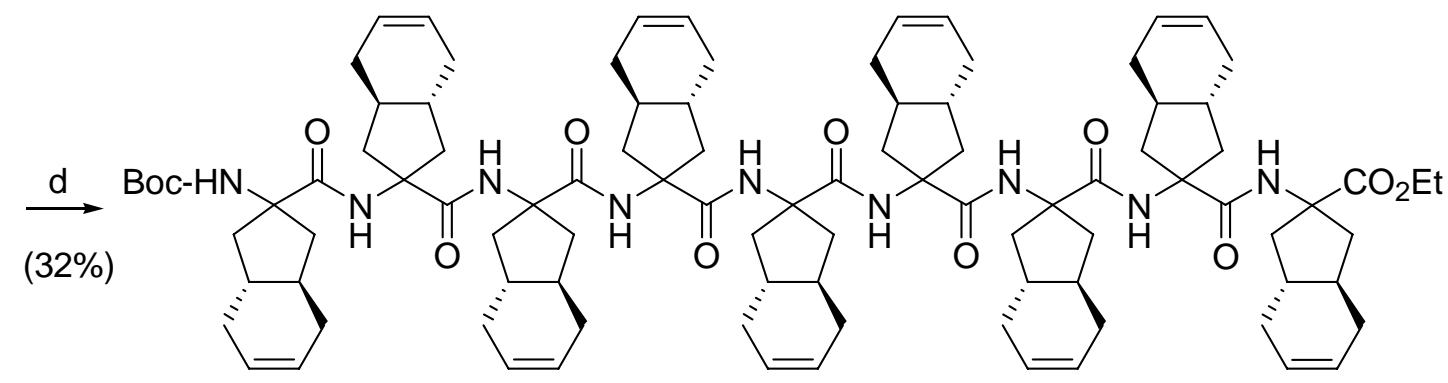

12: Boc- $\left[(R, R)-\mathrm{Ab}_{5,6}=\mathrm{C}\right]_{9}-\mathrm{OEt}$

Reagents: (a) HBTU, DIEA; (b) 1) conc. $\mathrm{HCl}$, EtOAc, 2) 5, HBTU, DIEA; (c) $\mathrm{NaOH}$; (d) 1) conc. $\mathrm{HCl}$, EtOAc, 2) Boc-[(R,R)-A $\left.b_{5,6}=\mathrm{c}\right]_{3}-\mathrm{OH}, \mathrm{HBTU}$, DIEA. 


\section{Experimental Section}

General. (S,S)-Cyclohex-4-ene-1,2-dicarboxylic acid (1) was prepared according to the known methods. ${ }^{6}$ Optical rotations $[\alpha]_{\mathrm{D}}$ were measured with a Jasco DIP-316 polarimeter using a $1.0 \mathrm{dm}$ cell. Circular dichroism spectra (CD) were measured with a Jasco J-720W spectropolarimeter using $1.0 \mathrm{~mm}$ path length cell. Infrared spectra (IR) were recorded on a Nicolet Avatar-320 spectrometer for conventional measurement ( $\mathrm{KBr}$, or neat), and the solution $\left(\mathrm{CDCl}_{3}\right)$ method using $0.1 \mathrm{~mm}$ path length of $\mathrm{NaCl}$ cell. ${ }^{1} \mathrm{H} \mathrm{NMR}$ spectra were determined at 400 or $500 \mathrm{MHz}$ (Varian Unity). EI-MS and FAB-MS spectra were taken on a Jeol JMS 610H or Jeol JMS-SX 102 spectrometer. Elemental analyses were performed at the Analytical Center of the Faculty of Sciences, Kyushu University.

(S,S)-Cyclohex-4-ene-1,2-dicarboxylic acid (1). ${ }^{6}$ Colorless crystals: $\mathrm{mp}$ 147-148 ${ }^{\circ} \mathrm{C}$; $[\alpha]^{26} \mathrm{D}=+142.0$ (c 1.10, EtOH) [lit. ${ }^{6}+160.0$ (c 2.70, EtOH); IR (KBr) 3100 (br), 2933, 1698, $1215 \mathrm{~cm}^{-1}$; ${ }^{1} \mathrm{H}$ NMR $\left(\mathrm{CDCl}_{3}\right) \delta 10.17$ (br, 2H), 5.73 (m, 2H), 2.83 (m, 2H), 2.45 (m, 2H), 2.28 (m, 2H); $\mathrm{FAB}(+) \mathrm{MS} \mathrm{m} / \mathrm{z} 171\left(\mathrm{M}^{+}+\mathrm{H}\right)$; Anal. Calcd for $\mathrm{C}_{8} \mathrm{H}_{10} \mathrm{O}_{4}$ : C, 56.47; H, 5.92. Found: C, 56.49; H, 5.83.

(4S,5S)-4,5-Bis(hydroxymethyl)cyclohexene. The carboxylic acid 1 (3.6 g, 21.2 mmol) was added portionwise to a rigorously stirred suspension of $\mathrm{LiAlH}_{4}(1.80 \mathrm{~g}, 46.5 \mathrm{mmol})$ in THF $(160 \mathrm{~mL})$ at $0{ }^{\circ} \mathrm{C}$. After being stirred at room temperature for $12 \mathrm{~h}$, the reaction was quenched with $15 \%$ aqueous $\mathrm{NaOH}$, and the resulting suspension was filtered off through celite. The filtrate was dried over $\mathrm{MgSO}_{4}$, and evaporated in vacuo to leave white solids, which were purified by column chromatography on silica gel. The fraction eluted with $5 \% \mathrm{MeOH}$ in $\mathrm{CHCl}_{3}$ afforded diol (2.60 g, 86\%) as colorless crystals: $\operatorname{mp~} 53-54{ }^{\circ} \mathrm{C} ;[\alpha]^{26}{ }_{\mathrm{D}}=+66.5$ (c 1.00, EtOH); IR (KBr) 3300 (br), 3025, 2959, $2916 \mathrm{~cm}^{-1}$; ${ }^{1} \mathrm{H}$ NMR (400 MHz, $\mathrm{CDCl}_{3}$ ) $\delta 5.65$ (m, 2H), 3.83 (br, 2H),3.70 (d, J = $11.0 \mathrm{~Hz}, 2 \mathrm{H}), 3.56$ (dd, $J=5.0,11.0 \mathrm{~Hz}, 2 \mathrm{H}), 2.02(\mathrm{~m}, 2 \mathrm{H}), 1.85$ (m, 2H), 1.68 (br s, 2H); 
FAB(+)MS m/z $143\left(\mathrm{M}^{+}+\mathrm{H}\right)$; Anal. Calcd for $\mathrm{C}_{8} \mathrm{H}_{14} \mathrm{O}_{2}$ : C, 67.57; H, 9.92. Found: C, 67.12; $\mathrm{H}$, 9.94 .

(4S,5S)-4,5-Bis(iodomethyl)cyclohexene (2). A solution of the diol (2.50 g, $17.6 \mathrm{mmol})$, $\mathrm{PPh}_{3}(18.4 \mathrm{~g}, 70.3 \mathrm{mmol})$, imidazole $(7.2 \mathrm{~g}, 105.5 \mathrm{mmol})$, and $\mathrm{I}_{2}(22.3 \mathrm{~g}, 87.9 \mathrm{mmol})$ in THF (200 $\mathrm{mL}$ ) was stirred at room temperature for $3 \mathrm{~h}$. The solution was diluted with EtOAc, washed with water, saturated aqueous $\mathrm{Na}_{2} \mathrm{~S}_{2} \mathrm{O}_{3}$, aqueous $1 \mathrm{~N} \mathrm{HCl}, 5 \%$ aqueous $\mathrm{NaHCO}_{3}$, brine, and dried over $\mathrm{MgSO}_{4}$. After removal of the solvent, the residue was purified by column chromatography on silica gel (hexane) to give $2(6.20 \mathrm{~g}, 97 \%)$ as colorless crystals: $\mathrm{mp} 39-40{ }^{\circ} \mathrm{C} ;[\alpha]^{26}{ }_{\mathrm{D}}=+49.4(\mathrm{c}$ 1.13, EtOH); IR (KBr) 3023, 2951, 2898, 2833, 1257, 1202, $1173 \mathrm{~cm}^{-1}$; ${ }^{1} \mathrm{H}$ NMR (400 MHz, $\left.\mathrm{CDCl}_{3}\right) \delta 5.62(\mathrm{~m}, 2 \mathrm{H}), 3.37(\mathrm{dd}, J=4.3,10.3 \mathrm{~Hz}, 2 \mathrm{H}), 3.28(\mathrm{~d}, J=10.3 \mathrm{~Hz}, 2 \mathrm{H}), 2.02-2.08(\mathrm{~m}$, 4H), $1.42(\mathrm{~m}, 2 \mathrm{H})$; $\mathrm{FAB}(+) \mathrm{MS} \mathrm{m} / \mathrm{z} 362\left(\mathrm{M}^{+}+\mathrm{H}\right)$; Anal. Calcd for $\mathrm{C}_{8} \mathrm{H}_{12} \mathrm{I}_{2}$ : C, 26.54; $\mathrm{H}, 3.34$. Found: C, 26.52; H, 3.27.

Ethyl (1R,6R)-8-(tert-Butoxycarbonylamino)bicyclo[4.3.0]non-3-ene-8-carboxylate $\{3$; Boc- $\left.\left[(\boldsymbol{R}, \boldsymbol{R})-\mathbf{A b} \mathbf{b}_{5,6}=\mathbf{c}\right]-\mathbf{O E t}\right\} . \quad$ A solution of ethyl isocyanoacetate $(756 \mu \mathrm{l}, 6.92 \mathrm{mmol})$ and $2(2.27 \mathrm{~g}$, $6.29 \mathrm{mmol})$ in $\mathrm{Et}_{2} \mathrm{O}-\mathrm{DMF}(10 \mathrm{~mL} ; 9: 1)$ was added dropwise to the stirred suspension of $\mathrm{NaH}(423$ mg, $17.61 \mathrm{mmol})$ in $\mathrm{Et}_{2} \mathrm{O}-\mathrm{DMF}(40 \mathrm{~mL})$ at $0{ }^{\circ} \mathrm{C}$. After being stirred at $0{ }^{\circ} \mathrm{C}$ for $3 \mathrm{~h}$, the solution was diluted with $\mathrm{H}_{2} \mathrm{O}$, extracted with $\mathrm{Et}_{2} \mathrm{O}$, and dried over $\mathrm{MgSO}_{4}$. Removal of the solvent afforded an oily residue, which was purified by column chromatography on silica gel (30\% EtOA in hexane) to give alkylated isonitrile $(882 \mathrm{mg}, 64 \%)$ as a colorless oil: $[\alpha]^{26}{ }_{\mathrm{D}}=+98.8(\mathrm{c} 1.25$, EtOH); IR (neat) 3023, 2980, 2895, 2836, 2135, 1744, 1443, 1275, $1195 \mathrm{~cm}^{-1}$; ${ }^{1} \mathrm{H}$ NMR (400 MHz, $\left.\mathrm{CDCl}_{3}\right) \delta 5.70-5.71(\mathrm{~m}, 2 \mathrm{H}), 4.27(\mathrm{q}, J=7.1 \mathrm{~Hz}, 2 \mathrm{H}), 2.75(\mathrm{dd}, \mathrm{J}=7.7,13.0 \mathrm{~Hz}, 1 \mathrm{H}), 2.46$ (dd, J $=11.8,18.0 \mathrm{~Hz}, 1 \mathrm{H}), 2.27-2.34(\mathrm{~m}, 2 \mathrm{H}), 1.71(\mathrm{~m}, 1 \mathrm{H}), 1.80-1.98(\mathrm{~m}, 5 \mathrm{H}), 1.34(\mathrm{t}, J=7.1 \mathrm{~Hz}$, 3H); FAB(+)MS m/z $219\left(\mathrm{M}^{+}+\mathrm{H}\right)$. A solution of alkylated product $(1.70 \mathrm{~g}, 7.75 \mathrm{mmol})$ and concentrated aqueous $\mathrm{HCl}(4 \mathrm{~mL})$ in $\mathrm{EtOH}(50 \mathrm{~mL})$ was stirred at $0{ }^{\circ} \mathrm{C}$ for $3 \mathrm{~h}$. Then, the solution was neutralized with $5 \%$ aqueous $\mathrm{NaHCO}_{3}$, and $\mathrm{EtOH}$ was evaporated. The aqueous residue was 
extracted with EtOAc, and dried over $\mathrm{MgSO}_{4}$. Removal of the solvent afforded a crude amine, which was solved in dioxane $(80 \mathrm{~mL})$, and then $(\mathrm{Boc})_{2} \mathrm{O}(2.03 \mathrm{~g}, 9.30 \mathrm{mmol})$ and $\mathrm{Et}_{3} \mathrm{~N}(1.3 \mathrm{~mL}$, $9.32 \mathrm{mmol}$ ) were added. After being stirred at room temperature for $24 \mathrm{~h}$, the solution was evaporated, and diluted with EtOAc. The solution was washed with $1 \mathrm{~N}$ aqueous $\mathrm{HCl}, 5 \%$ aqueous $\mathrm{NaHCO}_{3}$, brine, and dried over $\mathrm{MgSO}_{4}$. After removal of the solvent, the oily residue was purified by column chromatography on silica gel. The fraction eluted with $30 \%$ EtOAc in hexane afforded $3(2.21 \mathrm{~g}, 92 \%)$ as colorless crystals: $\operatorname{mp~} 101-103{ }^{\circ} \mathrm{C} ;[\alpha]^{26}{ }_{\mathrm{D}}=+60.8(c 0.99$, EtOH); IR (KBr) 3350 (br), 3021, 2981, 1712, $1216 \mathrm{~cm}^{-1} ;{ }^{1} \mathrm{H}$ NMR (400 MHz, $\left.\mathrm{CDCl}_{3}\right) \delta 5.63-$ 5.66 (m, 2H), 5.01 (br s, 1H), 4.16 (q, $J=7.0 \mathrm{~Hz}, 2 \mathrm{H}), 2.62$ (dd, $J=6.0,13.3 \mathrm{~Hz}, 1 \mathrm{H}), 2.22-2.26$ (m, 2H), $2.10(\mathrm{~m}, 1 \mathrm{H})$ 1.79-1.93 (m, 5H) $1.49(\mathrm{~m}, 1 \mathrm{H}) 1.42(\mathrm{~s}, 9 \mathrm{H}) 1.24(\mathrm{t}, J=7.0 \mathrm{~Hz}, 3 \mathrm{H})$; FAB(+)MS m/z $310\left(\mathrm{M}^{+}+\mathrm{H}\right)$; $\mathrm{FAB}(+) \mathrm{HRMS}$ calcd for $\mathrm{C}_{17} \mathrm{H}_{28} \mathrm{O}_{4} \mathrm{~N}\left(\mathrm{M}^{+}+\mathrm{H}\right) 310.2018$, found 310.2006; Anal. Calcd for $\mathrm{C}_{17} \mathrm{H}_{27} \mathrm{O}_{4} \mathrm{~N}$ : C, 65.99; H, 8.80; N 4.53. Found: C, 65.90; H, 8.73; N, 4.50 .

Ethyl $(1 R, 6 R)-8$-Aminobicyclo[4.3.0]non-3-ene-8-carboxylate $\left\{4 ; \mathrm{H}_{2} \mathrm{~N}-\left[(R, R)-\mathrm{Ab}_{5,6}=\mathrm{c}\right]-\right.$ OEt\}. A solution of 3 (190 mg, $0.615 \mathrm{mmol})$ in concentrated aqueous $\mathrm{HCl}$ (3 mL) and EtOAc (9 $\mathrm{mL}$ ) was stirred at room temperature for $5 \mathrm{~h}$. The solution was neutralized with $5 \%$ aqueous $\mathrm{NaHCO}_{3}$, extracted with EtOAc, and dried over $\mathrm{MgSO}_{4}$. After removal of the solvent, the residue was purified by column chromatography on silica gel $\left(10 \% \mathrm{MeOH}\right.$ in $\left.\mathrm{CHCl}_{3}\right)$ to give 4 (127 mg, quant.) as a colorless oil: $[\alpha]^{29}=+93.3$ (c 0.30, EtOH); IR (neat) 3370 (br), 3302, 3020, 2958, 2906, 2832, 1727, 1441, 1266, $1189 \mathrm{~cm}^{-1}$; ${ }^{1} \mathrm{H}$ NMR (400 MHz, $\left.\mathrm{CDCl}_{3}\right) \delta 5.68-5.69$ (m, 2H), 4.17 (q, $J=7.1 \mathrm{~Hz}, 2 \mathrm{H}), 2.50$ (dd, $J=7.3,12.9 \mathrm{~Hz}, 1 \mathrm{H}), 2.24-2.29$ (m, 2H), $1.68-1.89$ (m, 8H), 1.28 (t, $J=7.1 \mathrm{~Hz}, 3 \mathrm{H}), 1.21(\mathrm{~m}, 1 \mathrm{H})$; FAB(+)HRMS calcd for $\mathrm{C}_{12} \mathrm{H}_{20} \mathrm{O}_{2} \mathrm{~N}\left(\mathrm{M}^{+}+\mathrm{H}\right) 210.1494$, found 210.1530.

$(1 R, 6 R)-8$-(tert-Butoxycarbonylamino)bicyclo[4.3.0]non-3-ene-8-carboxylic Acid $\quad\{5$; Boc- $\left.\left[(\boldsymbol{R}, \boldsymbol{R})-\mathbf{A b}_{5,6}=\mathbf{c}\right]-\mathbf{O H}\right\} . \quad$ A solution of $\mathbf{3}(186 \mathrm{mg}, 0.602 \mathrm{mmol})$ and $1 \mathrm{~N}$ aqueous $\mathrm{NaOH}(2.0 \mathrm{~mL}$, $2.0 \mathrm{mmol})$ in $\mathrm{MeOH}(12 \mathrm{~mL})$ was stirred at room temperature for $12 \mathrm{~h}$. Then, the solution was 
neutralized with $1 \mathrm{~N}$ aqueous $\mathrm{HCl}$, and $\mathrm{MeOH}$ was evaporated. The aqueous solution was extracted with EtOAc, and dried over $\mathrm{Na}_{2} \mathrm{SO}_{4}$. Removal of the solvent afforded 5 (170 mg, $>99 \%)$ as colorless crystals, which were used for next reaction without further purification. mp 88-90 ${ }^{\circ} \mathrm{C} ;[\alpha]^{24}=+49.0$ (c 1.02, EtOH); IR (KBr) 3333, 3023, 2981, 1710, 1681, 1529, 1172 $\mathrm{cm}^{-1}$; ${ }^{1} \mathrm{H}$ NMR (400 MHz, $\left.\mathrm{CDCl}_{3}\right) \delta 5.65-5.68$ (m, 2H), 5.09 (br s, 1H), $2.74(\mathrm{~m}, 1 \mathrm{H}), 2.29$ (m, 1H), 2.25 (m, 1H), 2.13 (m, 1H), 1.99 (m, 1H), 1.76-1.84 (m, 4H), 1.44 (br, 1H), 1.44 (s, 9H); FAB(+)HRMS calcd for $\mathrm{C}_{15} \mathrm{H}_{24} \mathrm{O}_{4} \mathrm{~N}\left(\mathrm{M}^{+}+\mathrm{H}\right)$ 282.1705, found 282.1747.

Ethyl (3R,4R)-1-(tert-Butoxycarbonylamino)-3,4-bis(hydroxyethyl)cyclopentanecarboxylate (6). Ozone gas was bubbled into a solution of 3 (60 mg, $0.194 \mathrm{mmol})$ in $\mathrm{MeOH}$ (4 $\mathrm{mL})$ and $\mathrm{CH}_{2} \mathrm{Cl}_{2}(6 \mathrm{~mL})$ at $-78{ }^{\circ} \mathrm{C}$, and the reaction was monitored by TLC. $\mathrm{NaBH}_{4}(32 \mathrm{mg}, 0.86$ mmol) was added portionwise to the solution at $-78{ }^{\circ} \mathrm{C}$. After being stirred at $-78{ }^{\circ} \mathrm{C}$ for $30 \mathrm{~min}$, the solution was gradually warmed to room temperature, and neutralized with $1 \mathrm{~N}$ aqueous $\mathrm{HCl}$. After evaporation of $\mathrm{MeOH}$ and $\mathrm{CH}_{2} \mathrm{Cl}_{2}$, the aqueous solution was extracted with $\mathrm{CHCl}_{3}$, and dried over $\mathrm{MgSO}_{4}$. Removal of the solvent afforded a colorless oil, which was purified by column chromatography on silica gel. The fraction eluted with 5\% $\mathrm{MeOH}$ in $\mathrm{CHCl}_{3}$ gave 6 (59 mg, 63\%) as a colorless oil: $[\alpha]^{25}=-35.3$ (c 1.00, EtOH); IR (neat) 3350 (br), 2977, 2932, 1720, 1699, 1519, 1168, $1050 \mathrm{~cm}^{-1}$; ${ }^{1} \mathrm{H}$ NMR (400 MHz, $\mathrm{CDCl}_{3}$ ) $\delta 5.18$ (br s, $\left.1 \mathrm{H}\right), 4.17$ (q, $\left.J=7.1 \mathrm{~Hz}, 2 \mathrm{H}\right)$, 3.59-3.74 (m, 4H), 2.57 (dd, $J=8.1,13.7 \mathrm{~Hz}, 1 \mathrm{H}), 1.81-2.20$ (m, 9H), 1.58 (m, 1H), 1.48 (m, 1H), 1.43 (s, 9H), 1.26 (t, $J=7.1 \mathrm{~Hz}, 3 \mathrm{H})$; FAB(+)HRMS calcd for $\mathrm{C}_{17} \mathrm{H}_{32} \mathrm{O}_{6} \mathrm{~N}\left(\mathrm{M}^{+}+\mathrm{H}\right) 346.2230$, found 346.2199.

\section{Ethyl}

(3R,4R)-1-(tert-Butoxycarbonylamino)-3,4-bis(carboxymethyl)-

cyclopentanecarboxylate (7). Ozone gas was bubbled into a solution of 3 (50 mg, $0.162 \mathrm{mmol}$ ) in $\mathrm{MeOH}(9 \mathrm{~mL})$ and $\mathrm{CH}_{2} \mathrm{Cl}_{2}(1 \mathrm{~mL})$ at $-78^{\circ} \mathrm{C}$, and the reaction was monitored by TLC. $\mathrm{Me}_{2} \mathrm{~S}$ $(0.2 \mathrm{~mL})$ was added to the solution at $-78^{\circ} \mathrm{C}$, and the solution was warmed to room temperature. 
Removal of the solvent afforded a crude aldehyde. The crude aldehyde and oxone ${ }^{\circledR}$ (104 mg, $0.169 \mathrm{mmol}$ ) in DMF (4 mL) was stirred at room temperature for $5 \mathrm{~h}$. The solution was acidified with $1 \mathrm{~N}$ aqueous $\mathrm{HCl}$, extracted with EtOAc, and dried over $\mathrm{Na}_{2} \mathrm{SO}_{4}$. After removal of the solvent, the residue was purified by column chromatography on silica gel (5\% $\mathrm{MeOH}$ in $\left.\mathrm{CHCl}_{3}\right)$ to give 7 (24 mg, 40\%) as a colorless oil: $[\alpha]^{25}=-16.9\left(c\right.$ 0.72, $\left.\mathrm{CHCl}_{3}\right)$; IR (neat) 3368 (br), 2980, 1713, 1369, $1167 \mathrm{~cm}^{-1}$; ${ }^{1} \mathrm{H}$ NMR (400 MHz, $\left.\mathrm{CDCl}_{3}\right) \delta 5.13(\mathrm{br}, 1 \mathrm{H}), 4.19(\mathrm{q}, J=7.1 \mathrm{~Hz}, 2 \mathrm{H})$, 1.45-2.61 (m, 12H), 1.43 (s, 9H), 1.27 (t, $J=7.1 \mathrm{~Hz}, 3 \mathrm{H}) ; \mathrm{EI}(+) \mathrm{MS} \mathrm{m} / \mathrm{z} 300.3\left(\left[\mathrm{M}-\mathrm{OBu}^{t}\right]^{+}, 4\right)$, 241.2 (19), 149.1 (15), 83.0 (100).

Ethyl (1R,7R)-N-Benzyl-9-(tert-butoxycarbonylamino)-4-azabicyclo[5.3.0]decane-9carboxylate (8). Crude aldehyde, which was prepared from 3 (50 mg, $0.162 \mathrm{mmol}$ ) by the same procedure, was dissolved in $\mathrm{CH}_{2} \mathrm{Cl}_{2}(3 \mathrm{~mL})$ and $\mathrm{MeOH}(3 \mathrm{~mL}) . \mathrm{BnNH}_{2}(44 \mu \mathrm{L}, 0.40 \mathrm{mmol})$ was added to the solution, and the solution was stirred at room temperature for $30 \mathrm{~min}$, and then $\mathrm{NaBH}_{3} \mathrm{CN}$ (25 mg, $0.40 \mathrm{mmol}$ ) was added. After being stirred at room temperature for $12 \mathrm{~h}$, the solution was diluted with $\mathrm{H}_{2} \mathrm{O}$, extracted with $\mathrm{CHCl}_{3}$, and dried over $\mathrm{MgSO}_{4}$. Removal of the solvent afforded an oily residue, which was purified by column chromatography on silica gel (10\% EtOAc in hexane) to give 8 (35 mg, 53\%) as a colorless oil: $[\alpha]^{24}=-6.90\left(c 0.17, \mathrm{CHCl}_{3}\right)$; IR (neat) 3366 (br), 3026, 2976, 2930, 1716 (br), 1495, 1453, 1366, $1170 \mathrm{~cm}^{-1}$; ${ }^{1} \mathrm{H}$ NMR (400 MHz, $\left.\mathrm{CDCl}_{3}\right) \delta 7.21-7.35$ (m, 5H), 4.95 (br s, 1H), 4.18 (q, $\left.J=7.1 \mathrm{~Hz}, 2 \mathrm{H}\right), 3.65$ (s, 2H), 2.54—2.74 (m, 5H), $1.82-2.12(\mathrm{~m}, 7 \mathrm{H}), 1.55(\mathrm{~m}, 1 \mathrm{H}), 1.44(\mathrm{~s}, 9 \mathrm{H}), 1.36(\mathrm{~m}, 1 \mathrm{H}), 1.27(\mathrm{t}, J=7.1 \mathrm{~Hz}, 3 \mathrm{H})$; FAB(+)HRMS calcd for $\mathrm{C}_{24} \mathrm{H}_{37} \mathrm{O}_{4} \mathrm{~N}_{2}\left(\mathrm{M}^{+}+\mathrm{H}\right)$ 417.2753, found 417.2767.

Ethyl (1R,6R)-8-(tert-Butoxycarbonylamino)bicyclo[4.3.0]nonane-8-carboxylate \{9; Boc$\left.\left[(\boldsymbol{R}, \boldsymbol{R})-\mathbf{A b}_{5,6} \mathbf{c}\right]-\mathbf{O E t}\right\}$. A suspension of 3 (23 mg, $\left.0.074 \mathrm{mmol}\right)$ and 5\%Pd-C (50 mg) in MeOH (5 $\mathrm{mL}$ ) was stirred at room temperature under $\mathrm{H}_{2}$ atmosphere for $24 \mathrm{~h}$. Then, the catalyst was filtered off, and the filtrate was evaporated. The residue was purified by column chromatography 
on silica gel (10\% EtOAc in hexane) to give 9 (24 mg, >99\%) as colorless crystals: mp 53 - $54{ }^{\circ} \mathrm{C}$; $[\alpha]^{26}=-6.35$ (c 1.14, EtOH); IR (KBr) 3346, 2977, 2930, 2851, 1728, 1686, 1522, 1289, 1183 $\mathrm{cm}^{-1} ;{ }^{1} \mathrm{H}$ NMR (400 MHz, $\mathrm{CDCl}_{3}$ ) $\delta 5.01$ (br s, 1H), 4.18 (q, $\left.J=7.1 \mathrm{~Hz}, 2 \mathrm{H}\right), 2.51$ (m, 1H), 1.71$2.00(\mathrm{~m}, 7 \mathrm{H}), 1.43$ (s, 9H), 1.35-1.42 (m, 2H), $1.26(\mathrm{t}, \mathrm{J}=7.1 \mathrm{~Hz}, 3 \mathrm{H}), 1.15-1.25(\mathrm{~m}, 2 \mathrm{H})$, 0.98-1.15 (m, 2H); FAB(+)MS m/z $312\left(\mathrm{M}^{+}+\mathrm{H}\right)$; Anal. Calcd for $\mathrm{C}_{17} \mathrm{H}_{29} \mathrm{O}_{4} \mathrm{~N}$ : C, 65.57; H, 9.39; N 4.50. Found: C, 65.52; H, 9.31; N, 4.42.

Ethyl 8-\{[(1R,6R)-8-(tert-Butoxycarbonylamino)bicyclo[4.3.0]non-3-en-8yl]carbonylamino\}-(1R,6R)-bicyclo[4.3.0]non-3-ene-8-carboxylate $\quad$ ddipeptide; Boc-[(R,R)$\mathbf{A b}_{5,6=\mathbf{c}} \mathbf{l}_{2}$-OEt. A mixture of 4 (100 mg, $\left.0.50 \mathrm{mmol}\right), 5$ (170 mg, $\left.0.60 \mathrm{mmol}\right)$, HBTU (228 mg, $0.60 \mathrm{mmol})$, and DIEA $(174 \mu \mathrm{l}, 1.00 \mathrm{mmol})$ in $\mathrm{CH}_{2} \mathrm{Cl}_{2}(5 \mathrm{~mL})$ was stirred at $40{ }^{\circ} \mathrm{C}$ for $5 \mathrm{~h}$. Then, the solution was diluted with EtOAc, washed with $1 \mathrm{~N}$ aqueous $\mathrm{HCl}, 5 \%$ aqueous $\mathrm{NaHCO}_{3}$, brine, and dried over $\mathrm{MgSO}_{4}$. Removal of the solvent afforded white solids, which were purified by column chromatography on silica gel $\left(1 \% \mathrm{MeOH}\right.$ in $\left.\mathrm{CHCl}_{3}\right)$ to give dipeptide (148 $\left.\mathrm{mg}, 62 \%\right)$ as colorless crystals: $\quad \operatorname{mp} 209-210{ }^{\circ} \mathrm{C} ;[\alpha]^{22}=+85.3\left(c\right.$ 0.38, $\left.\mathrm{CHCl}_{3}\right)$; IR $\left(\mathrm{CDCl}_{3}\right) 3437$ (br), 3024, 2914, 2836, 1718, 1684, $1161 \mathrm{~cm}^{-1}$; ${ }^{1} \mathrm{H}$ NMR (400 MHz, $\mathrm{CDCl}_{3}$ ) $\delta 7.26$ (br s, 1H), 5.60—5.67 (m, 4H), 4.92 (br s, 1H), 4.17 (q, $J=7.2 \mathrm{~Hz}, 2 \mathrm{H}), 2.80$ (m, 1H), 2.61 (m, 1H), 2.17-2.24 (m, 5H) 1.30-2.05 (m, 13H), 1.44 (s, 9H), 1.24 (t, $J=7.2 \mathrm{~Hz}, 3 \mathrm{H})$; FAB(+)MS m/z $473\left(\mathrm{M}^{+}+\mathrm{H}\right)$; Anal. Calcd for $\mathrm{C}_{27} \mathrm{H}_{40} \mathrm{O}_{6} \mathrm{~N}_{2}$ : C, 68.62; H, 8.53; N 5.93. Found: C, 68.32; H, 8.45; N, 6.05.

Ethyl 8-[(8-\{[(1R,6R)-8-(tert-Butoxycarbonylamino)bicyclo[4.3.0]non-3-en-8yl]carbonylamino\}-(1R,6R)-bicyclo[4.3.0]non-3-en-8-yl)carbonylamino]-(1R,6R)-

bicyclo[4.3.0]non-3-ene-8-carboxylate \{tripeptide 10; Boc- $\left[(R, R)-\mathrm{Ab}_{5,6}=\mathrm{C}\right]_{3}-\mathrm{OEt} . \quad$ A mixture of dipeptide (156 mg, $0.330 \mathrm{mmol})$ in concentrated aqueous $\mathrm{HCl}(2 \mathrm{~mL})$ and EtOAc $(6 \mathrm{~mL})$ was stirred at room temperature for $5 \mathrm{~h}$. The solution was neutralized with $5 \%$ aqueous $\mathrm{NaHCO}_{3}$, extracted with EtOAc, and dried over $\mathrm{MgSO}_{4}$. After removal of the solvent, the residue was 
filtered through short silica gel column $\left(10 \% \mathrm{MeOH}\right.$ in $\left.\mathrm{CHCl}_{3}\right)$ to leave an amine (114 mg). A solution of the amine (114 mg, $307 \mathrm{mmol})$, monoacid 5 (103 mg, $0.367 \mathrm{mmol})$, HBTU (140 mg, $0.370 \mathrm{mmol})$, and DIEA $(0.10 \mathrm{~mL}, 0.60 \mathrm{mmol})$ in $\mathrm{CH}_{2} \mathrm{Cl}_{2}(10 \mathrm{~mL})$ was stirred at $40{ }^{\circ} \mathrm{C}$ for $48 \mathrm{~h}$. Then, the solution was diluted with $\mathrm{CHCl}_{3}$, washed with $1 \mathrm{~N}$ aqueous $\mathrm{HCl}, 5 \%$ aqueous $\mathrm{NaHCO}_{3}$, brine, and dried over $\mathrm{MgSO}_{4}$. After removal of the solvent, the residue was purified by column chromatography on silica gel $\left(5 \% \mathrm{MeOH}\right.$ in $\left.\mathrm{CHCl}_{3}\right)$ to give tripeptide 10 (165 mg, 85\%) as colorless crystals: $\mathrm{mp} 238-239{ }^{\circ} \mathrm{C}$ (recryst. from $\left.\mathrm{CHCl}_{3}\right) ;[\alpha]^{24}{ }_{\mathrm{D}}=+70.6\left(\mathrm{c} 0.85, \mathrm{CHCl}_{3}\right)$; IR $\left(\mathrm{CDCl}_{3}\right) 3433$ (br), 3365 (br), 3024, 2913, 2835, 1720, 1706, 1521, 1271, $1160 \mathrm{~cm}^{-1}$; ${ }^{1} \mathrm{H}$ NMR (400 MHz, $\mathrm{CDCl}_{3}$ ) $\delta 7.66$ (br s, 1H), 6.59 (br s, 1H), 5.63—5.66 (m, 6H), 5.07 (br s, 1H), 4.10— $4.17(\mathrm{~m}, 2 \mathrm{H}), 2.72-2.87(\mathrm{~m}, 3 \mathrm{H}), 2.20-2.38(\mathrm{~m}, 7 \mathrm{H}), 1.50-2.17(\mathrm{~m}, 17 \mathrm{H}), 1.47$ (s, 9H) $1.20-$ 1.31 (m, 6H); FAB(+)HRMS calcd for $\mathrm{C}_{37} \mathrm{H}_{54} \mathrm{O}_{6} \mathrm{~N}_{3}\left(\mathrm{M}^{+}+\mathrm{H}\right)$ 636.4013, found 636.4017.

\section{8-[(8-\{[(1R,6R)-8-(tert-Butoxycarbonylamino)bicyclo[4.3.0]non-3-en-8-}

\section{yl]carbonylamino\}-(1R,6R)-bicyclo[4.3.0]non-3-en-8-yl)carbonylamino]-(1R,6R)-}

bicyclo[4.3.0]non-3-ene-8-carboxylic Acid $\left\{\right.$ Boc- $\left.\left[(R, R)-\mathrm{Ab}_{5,6}=\mathbf{c}\right]_{3}-\mathbf{O H}\right\} . \quad$ A solution of tripeptide 10 (35 mg, $55 \mu \mathrm{mol}$ ) in $1 \mathrm{~N}$ aqueous $\mathrm{NaOH}(2.0 \mathrm{~mL}, 2.0 \mathrm{mmol}$ ) and $\mathrm{MeOH}(6 \mathrm{~mL})$ was stirred at 60 ${ }^{\circ} \mathrm{C}$ for $12 \mathrm{~h}$. Then, the solution was neutralized with $1 \mathrm{~N}$ aqueous $\mathrm{HCl}$, and $\mathrm{MeOH}$ was evaporated. The aqueous residue was extracted with EtOAc, and dried over $\mathrm{Na}_{2} \mathrm{SO}_{4}$. Removal of the solvent gave crude tripeptide acid, which was used for the next reaction without purification. mp 148$149{ }^{\circ} \mathrm{C} ;[\alpha]^{23}{ }_{\mathrm{D}}=+112.6$ (c 0.88, $\mathrm{CHCl}_{3}$ ); IR (KBr) 3323 (br), 3021, 2907, 1684 (br), 1520, 1167 $\mathrm{cm}^{-1}$; ${ }^{1} \mathrm{H}$ NMR (400 MHz, $\mathrm{CDCl}_{3}$ ) $\delta 11.0$ (br, 1H), 7.77 (br s, 1H), 6.88 (br s, 1H), 5.63-5.66 (m, 6H), 5.31 (br s, 1H), 2.80-2.93 (m, 3H), 2.46 (m, 1H), 2.21-2.29 (m, 7H), 1.60-2.09 (m, 15H), $1.46(\mathrm{~s}, 9 \mathrm{H}) 1.10-1.30(\mathrm{~m}, 4 \mathrm{H})$; $\mathrm{FAB}(+) \mathrm{HRMS}$ calcd for $\mathrm{C}_{35} \mathrm{H}_{50} \mathrm{O}_{6} \mathrm{~N}_{3}\left(\mathrm{M}^{+}+\mathrm{H}\right)$ 608.3700, found 608.3693. 
Ethyl 8-\{\{8-\{\{8-\{\{8-\{\{8-\{[(1R,6R)-8-(tert-Butoxycarbonylamino)bicyclo[4.3.0]non-3-en-8yl]carbonylamino\}-(1R,6R)-bicyclo[4.3.0]non-3-en-8-yl\}carbonylamino\}-(1R,6R)bicyclo[4.3.0]non-3-en-8-yl\}carbonylamino\}-(1R,6R)-bicyclo[4.3.0]non-3-en-8yl\}carbonylamino\}-(1R,6R)-bicyclo[4.3.0]non-3-en-8-yl\}carbonylamino\}-(1R,6R)bicyclo[4.3.0]non-3-ene-8-carboxylate $\left\{\right.$ hexapeptide 11; Boc- $\left.\left[(R, R)-\mathrm{Ab}_{5,6}=\mathrm{C}\right]_{6}-\mathrm{OEt}\right\} . \quad$ Aqueous concentrated $\mathrm{HCl}(0.7 \mathrm{~mL})$ was added dropwise to the stirred solution of tripeptide $\mathbf{1 0}$ (30 $\mathrm{mg}, 47$ $\mu \mathrm{mol})$ in EtOAc $(2 \mathrm{~mL})$ at $0{ }^{\circ} \mathrm{C}$. After being stirred at room temperature for $5 \mathrm{~h}$, the solution was neutralized with $5 \%$ aqueous $\mathrm{NaHCO}_{3}$, extracted with EtOAc, and dried over $\mathrm{MgSO}_{4}$. Removal of the solvent afforded a residue, which was purified by short column chromatography on silica gel (10\% $\mathrm{MeOH}$ in $\mathrm{CHCl}_{3}$ ) to give an $\mathrm{N}$-terminal free tripeptide. A mixture of tripeptide acid (33 mg, $55 \mu \mathrm{mol}), \mathrm{HBTU}$ (21 mg, $55 \mu \mathrm{mol})$, DIEA (16 $\mu \mathrm{l}, 94 \mu \mathrm{mol})$ in $\mathrm{CH}_{2} \mathrm{Cl}_{2}(2 \mathrm{~mL})$ was added to the stirred solution of the $\mathrm{N}$-terminal free tripeptide in $\mathrm{CH}_{2} \mathrm{Cl}_{2}(3 \mathrm{~mL})$ at room temperature. After being stirred at $40{ }^{\circ} \mathrm{C}$ for $48 \mathrm{~h}$, the solution was diluted with $\mathrm{CHCl}_{3}$, washed with $1 \mathrm{~N}$ aqueous $\mathrm{HCl}$, 5\% aqueous $\mathrm{NaHCO}_{3}$, brine, and dried over $\mathrm{MgSO}_{4}$. Removal of the solvent afforded white solids, which were purified by column chromatography on silica gel $\left(5 \% \mathrm{MeOH}\right.$ in $\left.\mathrm{CHCl}_{3}\right)$ to give hexapeptide 11 (27 mg, 50\%) as colorless crystals: mp $240{ }^{\circ} \mathrm{C}$ (decomp.); $[\alpha]^{24}{ }_{\mathrm{D}}=+215.3(\mathrm{c}$ 0.64, $\mathrm{CHCl}_{3}$ ); IR (CDCl 3426 (br), 3332 (br), 2913, 2835, 1725, 1698, 1525, 1280, $1158 \mathrm{~cm}^{-1}$; ${ }^{1} \mathrm{H}$ NMR (500 MHz, CDCl 3 ) $\delta 8.16$ (br s, 1H), 7.91 (br s, 1H), 7.65 (br s, 1H), 7.57 (br s, 1H), 6.90 (br s, 1H), 5.60-5.70 (m, 12H), 5.32 (br s, 1H), 4.15 (m, 2H), 3.10-3.23 (m, 4H), 2.85 (m, 1H), 2.48-2.70 (m, 3H), 2.05-2.30 (m, 13H), 1.56-1.95 (m, 33H), 1.48 (s, 9H), 1.20-1.42 (m, 9H); FAB(+)MS m/z $1126\left(\mathrm{M}^{+}+\mathrm{H}\right)$; FAB(+)HRMS calcd for $\mathrm{C}_{67} \mathrm{H}_{92} \mathrm{O}_{9} \mathrm{~N}_{6} \mathrm{Na}\left(\mathrm{M}^{+}+\mathrm{Na}\right)$ 1147.6823, found 1147.6840 .

\section{Ethyl}

$8-\{\{8-\{\{8-\{\{8-\{\{8-\{\{8-\{\{8-\{\{8-\{[(1 R, 6 R)-8-(t e r t-$ Butoxycarbonylamino)bicyclo[4.3.0]non-3-en-8-yl]carbonylamino\}-(1R,6R)-bicyclo[4.3.0]non3-en-8-yl\}carbonylamino\}-(1R,6R)-bicyclo[4.3.0]non-3-en-8-yl\}carbonylamino\}-(1R,6R)- 
bicyclo[4.3.0]non-3-en-8-yl\}carbonylamino\}-(1R,6R)-bicyclo[4.3.0]non-3-en-8-

yl\}carbonylamino\}-(1R,6R)-bicyclo[4.3.0]non-3-en-8-yl\}carbonylamino\}-(1R,6R)-

bicyclo[4.3.0]non-3-en-8-yl\}carbonylamino\}-(1R,6R)-bicyclo[4.3.0]non-3-en-8-

yl\}carbonylamino\}-(1R,6R)-bicyclo[4.3.0]non-3-ene-8-carboxylate $\quad$ nnonapeptide 12; Boc$\left.\left[(\boldsymbol{R}, \boldsymbol{R})-\mathbf{A b}_{5,6}=\mathbf{c}\right]_{9}-\mathbf{O E t}\right\}$. Concentrated aqueous $\mathrm{HCl}(2 \mathrm{~mL})$ was added to the stirred solution of hexapeptide $11(90 \mathrm{mg}, 80 \mu \mathrm{mol})$ in EtOAc $(5 \mathrm{~mL})$ at $0{ }^{\circ} \mathrm{C}$. After being stirred at room temperature for $12 \mathrm{~h}$, the solution was neutralized with $5 \%$ aqueous $\mathrm{NaHCO}_{3}$, extracted with $\mathrm{CHCl}_{3}$, and dried over $\mathrm{MgSO}_{4}$. After removal of the solvent, the residue was purified by short column chromatography on silica gel $\left(10 \% \mathrm{MeOH}\right.$ in $\left.\mathrm{CHCl}_{3}\right)$ to leave an $\mathrm{N}$-terminal free hexapeptide (45 mg, $44 \mu \mathrm{mol}$ ). A solution of the hexapeptide amine (45 mg, $44 \mu \mathrm{mol}$ ), tripeptide acid (33 mg, 54 $\mu \mathrm{mol})$, HBTU (21 mg, $54 \mu \mathrm{mol})$, DIEA $(15 \mu \mathrm{l}, 86 \mu \mathrm{mol})$ in $\mathrm{CH}_{2} \mathrm{Cl}_{2}(5 \mathrm{~mL})$ was stirred at $40{ }^{\circ} \mathrm{C}$ for $48 \mathrm{~h}$. The solution was diluted with $\mathrm{CHCl}_{3}$, washed with $1 \mathrm{~N}$ aqueous $\mathrm{HCl}, 5 \%$ aqueous $\mathrm{NaHCO}_{3}$, brine, and dried over $\mathrm{MgSO}_{4}$. After removal of the solvent, the residue was purified by column chromatography on silica gel. The fraction eluted with $5 \% \mathrm{MeOH}$ in $\mathrm{CHCl}_{3}$ afforded nonapeptide 12 (42 mg, 32\%) as white powders: $\operatorname{mp~} 250{ }^{\circ} \mathrm{C}$ (decomp.); $[\alpha]^{26}{ }_{\mathrm{D}}=+247.1$ (c 0.20, $\mathrm{CHCl}_{3}$ ); IR $\left(\mathrm{CDCl}_{3}\right) 3424$ (br), 3314 (br), 3023, 2912, 2890, 1724, 1697, 1650, 1528, $1281 \mathrm{~cm}^{-1}$; ${ }^{1} \mathrm{H}$ NMR (400 MHz, $\mathrm{CDCl}_{3}$ ) $\delta 8.29$ (br s, 1H), 8.17 (br s, 1H), 8.12 (br s, 1H), 8.09 (br s, 1H), 7.96 (br s, 1H), 7.68 (br s, 1H), 7.64 (br s, 1H) 6.97 (br s, 1H), 5.34 (br s, 1H) 5.60—5.67 (m, 18H), 4.15 (m, 2H), 3.09-3.24 (m, 8H), 2.57-2.92 (m, 8H), 2.05-2.25 (m, 20H), 1.52-1.94 (m, 45H), 1.48 (s, 9H) $1.26-1.35$ (m, 12H); FAB(+)MS m/z $1638\left(\mathrm{M}^{+}+\mathrm{Na}\right)$.

Ethyl 8-\{\{8-\{\{8-\{\{8-\{\{8-\{[(1R,6R)-8-(tert-Butoxycarbonylamino)bicyclo[4.3.0]nonan-8yl]carbonylamino\}-(1R,6R)-bicyclo[4.3.0]nonan-8-yl\}carbonylamino\}-(1R,6R)bicyclo[4.3.0]nonan-8-yl\}carbonylamino\}-(1R,6R)-bicyclo[4.3.0]nonan-8-yl\}carbonylamino\}(1R,6R)-bicyclo[4.3.0]nonan-8-yl\}carbonylamino\}-(1R,6R)-bicyclo[4.3.0]nonane-8-carboxylate \{saturated hexapeptide 13; Boc-[(R,R)-A $\left.\mathbf{b}_{5,6} \mathbf{c}\right]_{6}-\mathbf{O E t}$ \}. A suspension of hexapeptide 11 (50 mg, 
$0.044 \mathrm{mmol})$ and $20 \% \mathrm{Pd}(\mathrm{OH})_{2}-\mathrm{C}(50 \mathrm{mg})$ in $\mathrm{MeOH}(9 \mathrm{~mL})$ and THF $(1 \mathrm{~mL})$ was stirred under $\mathrm{H}_{2}$ atmosphere for $24 \mathrm{~h}$. Then, the catalyst was filtered off, and the filtrate was evaporated. The residue was purified by column chromatography on silica gel $\left(5 \% \mathrm{MeOH}\right.$ in $\mathrm{CHCl}_{3}$ ) to give 13 (36 mg, 70\%) as colorless crystals: mp $272-273{ }^{\circ} \mathrm{C} ;[\alpha]_{\mathrm{D}}^{26}=+132.1\left(\right.$ c $\left.0.315, \mathrm{CHCl}_{3}\right) ; \mathrm{IR}\left(\mathrm{CDCl}_{3}\right)$ 3426 (br), 3336 (br), 2925, 2853, 1723, 1699, 1661, 1522, 1448, $1287 \mathrm{~cm}^{-1}$; ${ }^{1} \mathrm{H}$ NMR (500 MHz, $\left.\mathrm{CDCl}_{3}\right) \delta 8.12$ (br s, $1 \mathrm{H}$ ), 7.83 (br s, $1 \mathrm{H}$ ), 7.61 (br s, $1 \mathrm{H}$ ), 7.51 (br s, $1 \mathrm{H}$ ), 6.86 (br s, $\left.1 \mathrm{H}\right) 5.29$ (br s, 1H) $4.14(\mathrm{~m}, 2 \mathrm{H}), 2.97-3.10(\mathrm{~m}, 4 \mathrm{H}), 2.78(\mathrm{~m}, 1 \mathrm{H}), 2.34-2.58(\mathrm{~m}, 3 \mathrm{H}), 1.62-1.86(\mathrm{~m}, 33 \mathrm{H})$, $1.51(\mathrm{~s}, 9 \mathrm{H})$ 0.80-1.45 (m, 46H); FAB(+)MS m/z $1138\left(\mathrm{M}^{+}+\mathrm{H}\right) ; \mathrm{FAB}(+)$ HRMS calcd for $\mathrm{C}_{67} \mathrm{H}_{104} \mathrm{O}_{9} \mathrm{~N}_{6} \mathrm{Na}\left(\mathrm{M}^{+}+\mathrm{Na}\right)$ 1159.7762, found 1159.7736. 
Figure S1. Infrared (IR) spectra of Boc- $\left[(R, R)-\mathrm{Ab}_{5,6}=\mathrm{C}\right]_{\mathrm{n}}-\mathrm{OEt}(\mathrm{n}=1,2,3,6,9)$.

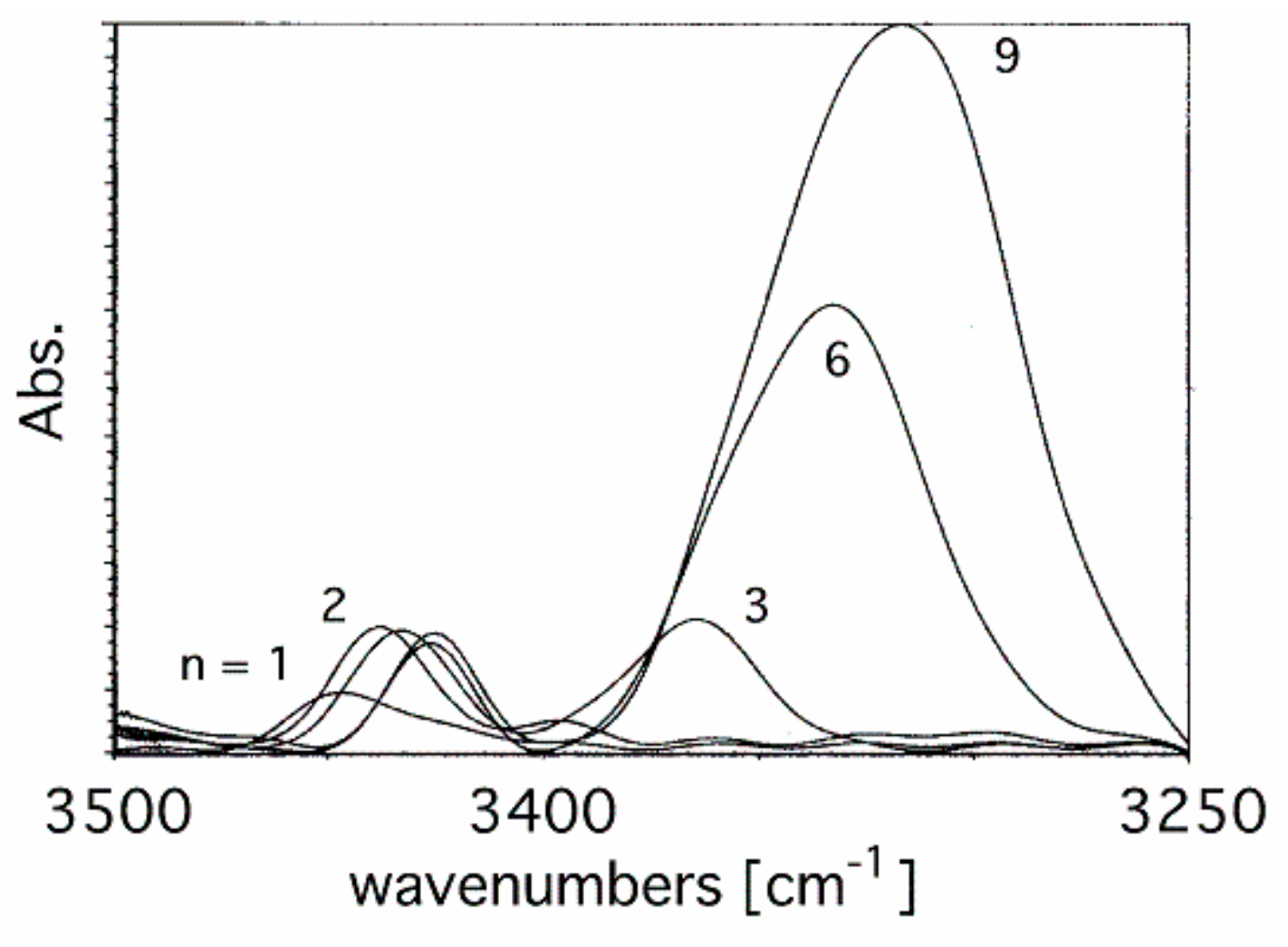

FT-IR absorption spectra in the $\mathrm{N}-\mathrm{H}$ stretching region of peptides; Boc- $\left[(R, R)-\mathrm{Ab}_{5,6=} \mathrm{C}\right]_{\mathrm{n}}$-OEt $(\mathrm{n}=1-9)$ 
Figure S2. $\quad{ }^{1} \mathrm{H}$ NMR experiments by adding radical TEMPO or DMSO to the $\mathrm{CDCl}_{3}$ solution of hexapeptide $\mathbf{1 1}$ and $\mathbf{1 3 .}$

a)

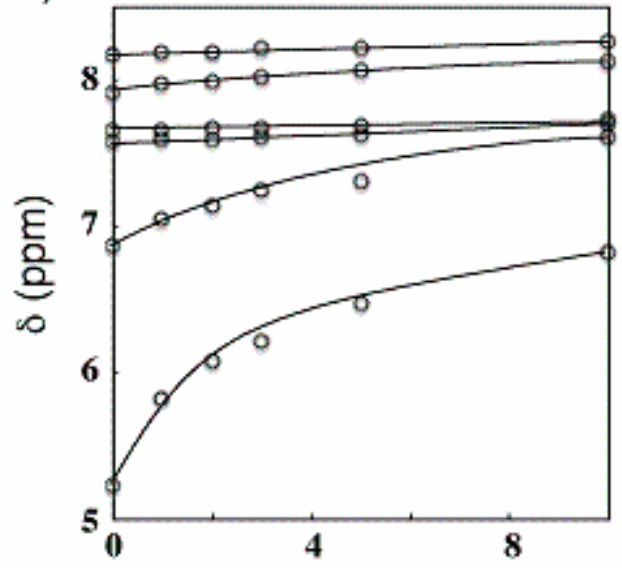

$\%$ DMSO in $\mathrm{CDCl}_{3}$ b)

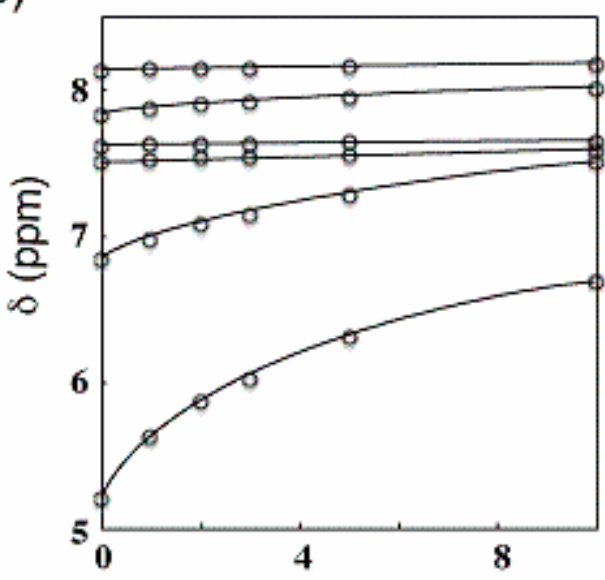

$\%$ DMSO in $\mathrm{CDCl}_{3}$

Plots of $\mathrm{NH}$ chemical shifts in the ${ }^{1} \mathrm{H}-\mathrm{NMR}$ spectra of peptides

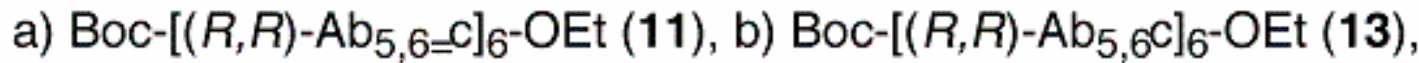
as a function of increasing percentage of DMSO $(\mathrm{v} / \mathrm{v})$ added to the $\mathrm{CDCl}_{3}$ solution. Peptides concentration; $1.0 \mathrm{mM}$.

c)

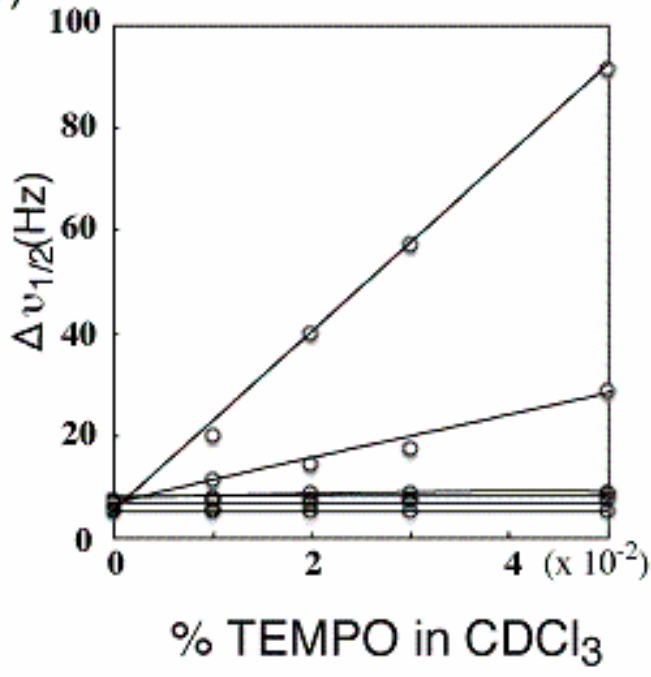

d)

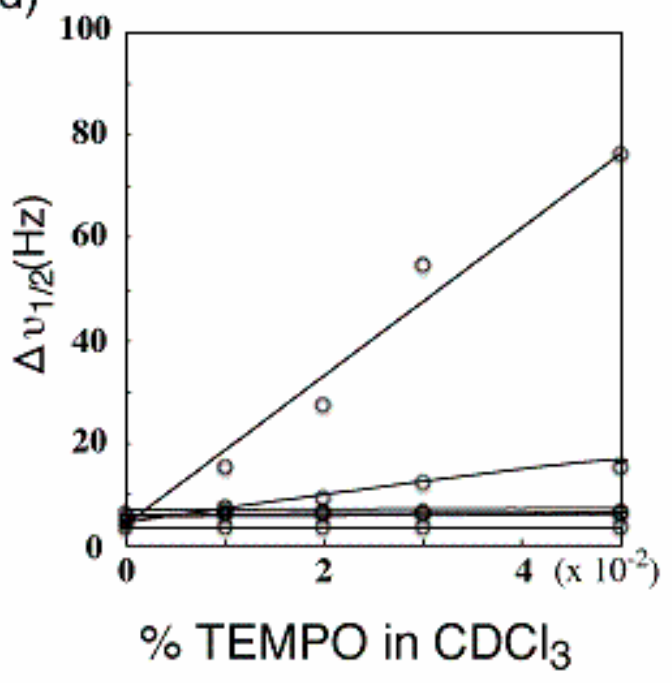

Plots of bandwidth of the $\mathrm{NH}$ protons of the peptides

c) Boc-[( $\left.R, R)-\mathrm{Ab}_{5,6=} \mathrm{c}\right]_{6}$-OEt (11), d) Boc-[( $\left.\left.R, R\right)-\mathrm{Ab}_{5,6} \mathrm{C}\right]_{6}$-OEt (13), as a function of increasing percentage of TEMPO $(\mathrm{w} / \mathrm{v})$ added to the $\mathrm{CDCl}_{3}$ solution. Peptides concentration; $1.0 \mathrm{mM}$. 
Figure S3. The rotating frame nuclear Overhauser effect spectroscopy (ROESY) ${ }^{1} \mathrm{H}$ NMR spectrum of hexapeptide Boc-[(R,R)-Ab $\left.b_{5,6=\mathrm{C}}\right]_{6}-\mathrm{OEt}$ (11).
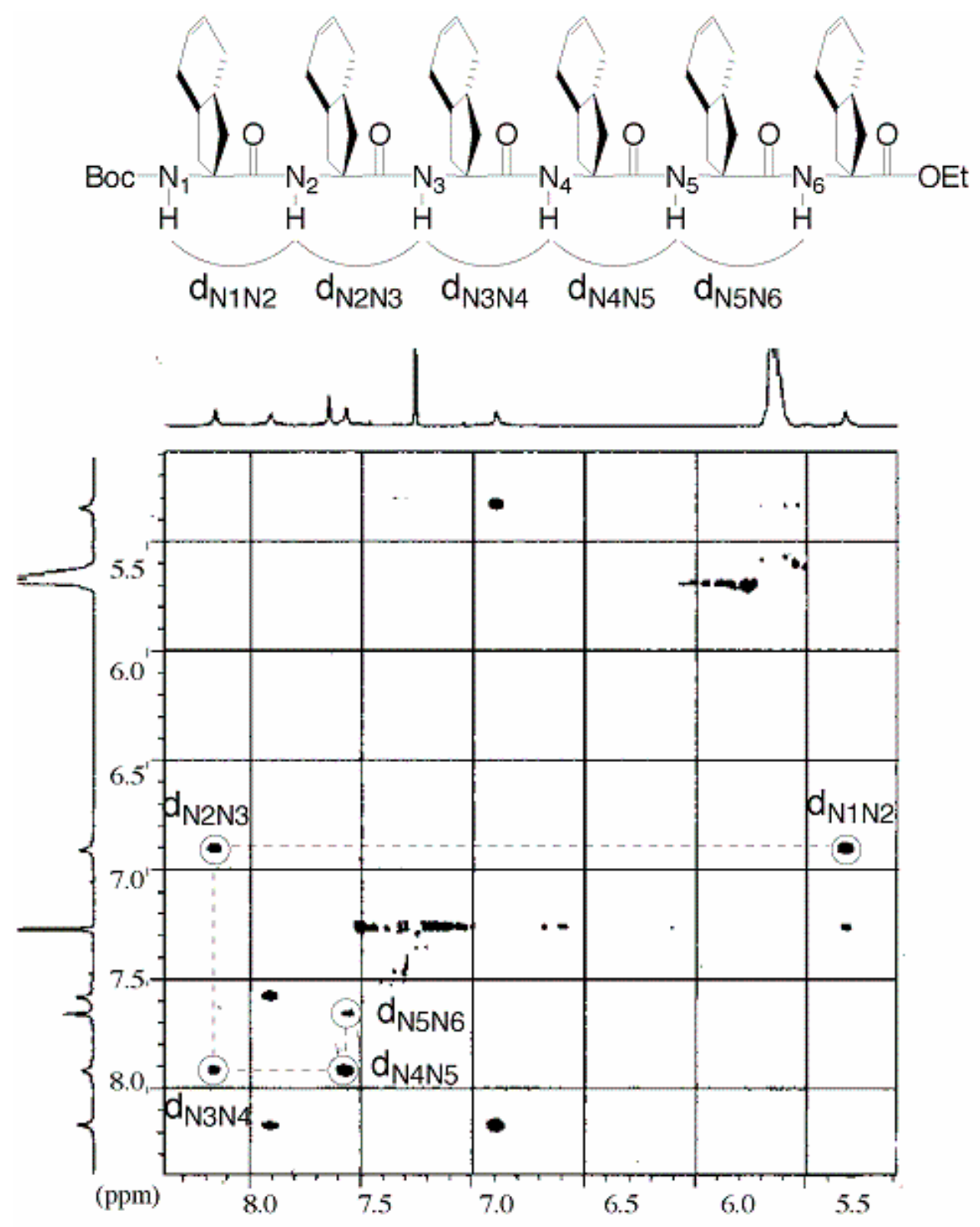

Amide proton region of the 2D ROESY spectrum of Boc- $\left[(R, R)-\mathrm{Ab}_{5,6=} \mathrm{c}\right]_{6}-\mathrm{OEt}(11), \tau=250 \mathrm{~ms}$. 
Figure S4. The ROESY ${ }^{1} \mathrm{H}$ NMR spectrum of nonapeptide (12).
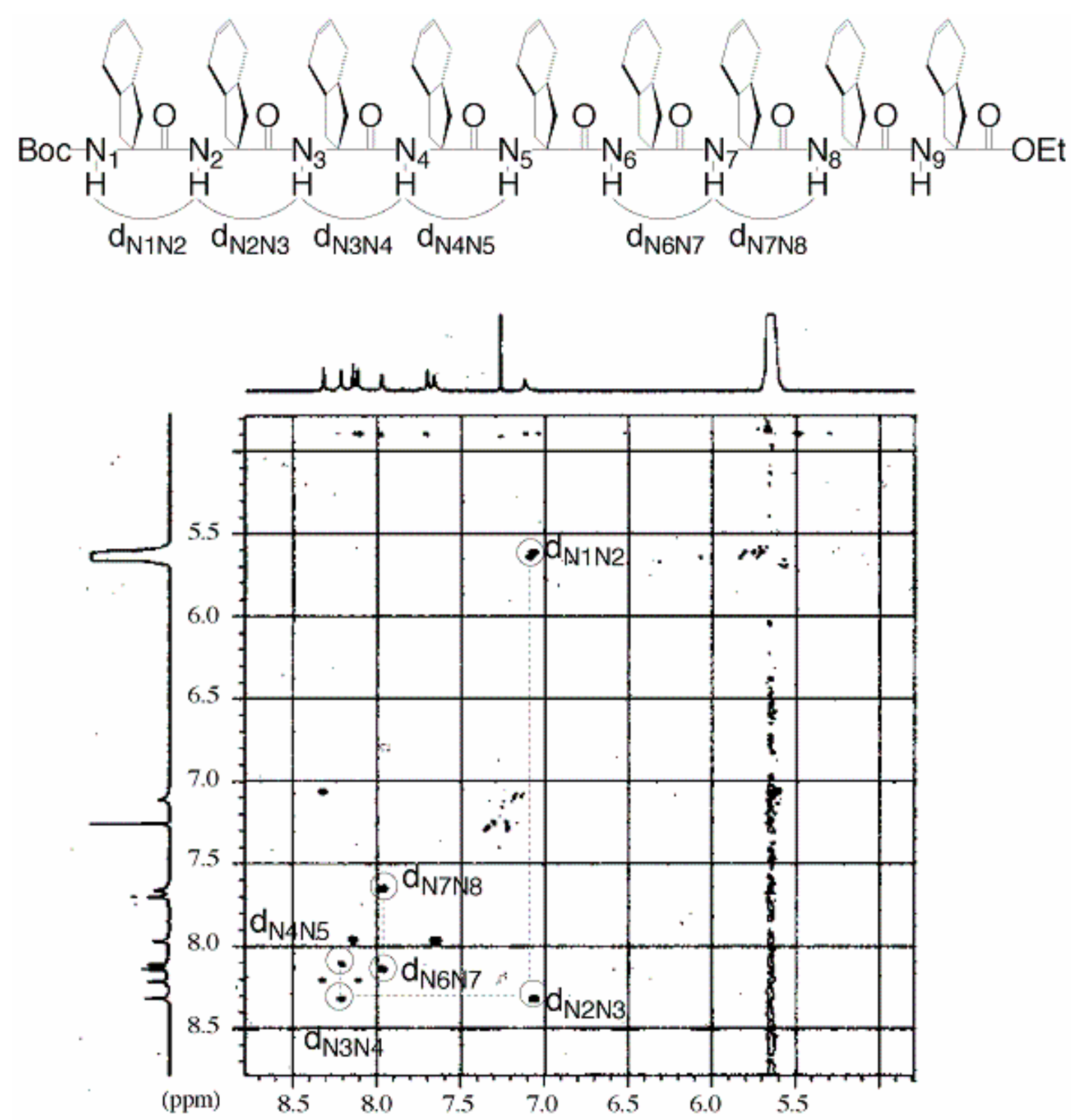

Amide proton region of the 2D ROESY spectrum of Boc- $\left[(R, R)-\mathrm{Ab}_{5,6=} \mathrm{c}\right]_{9}-\mathrm{OEt}(12), \tau=300 \mathrm{~ms}$. 
Fig. S5. CD spectra of 11, 12, and 13.

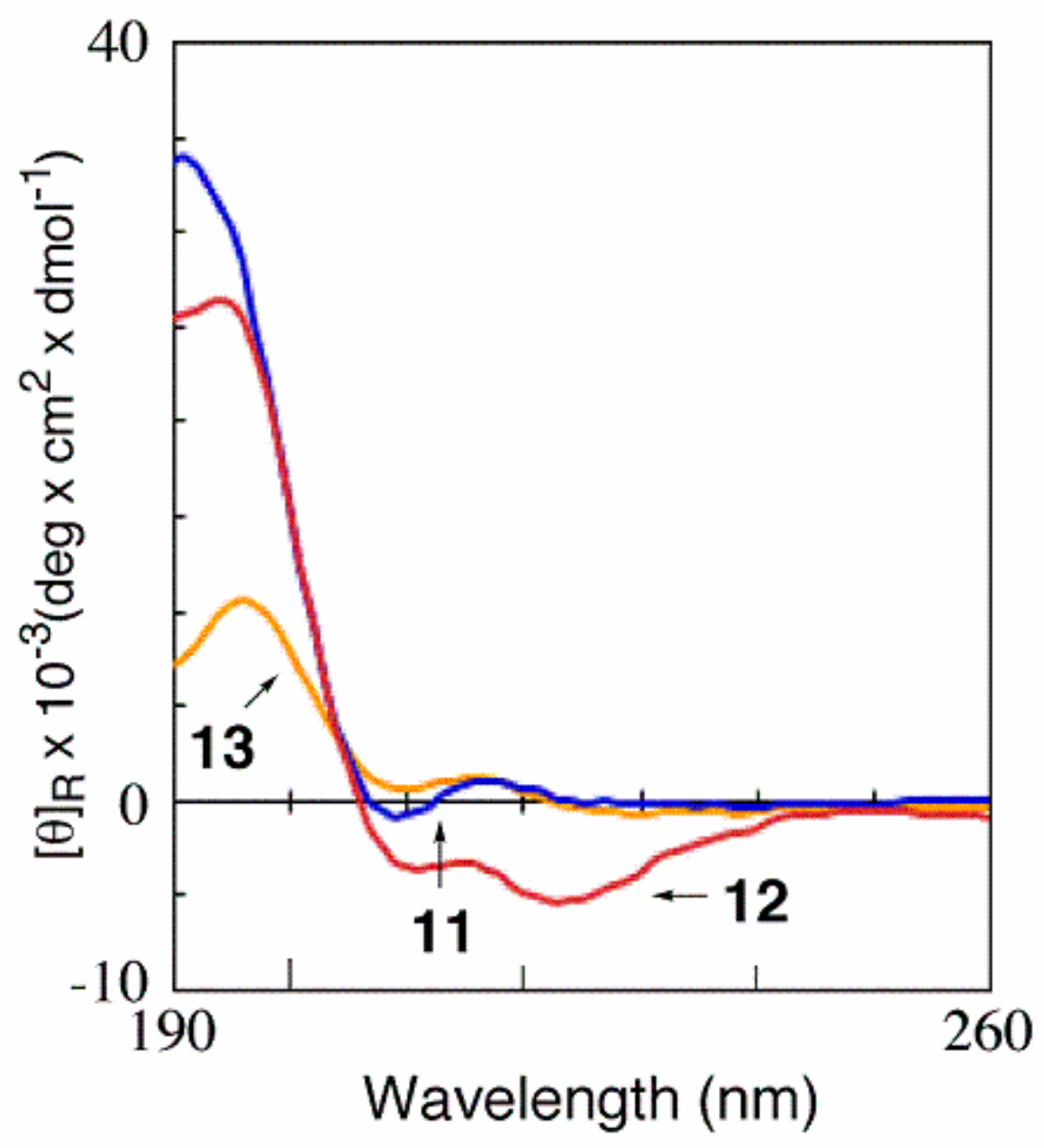

CD spectra of Boc- $\left[(R, R)-\mathrm{Ab}_{5,6}=\mathrm{C}\right]_{\mathrm{n}}-\mathrm{OEt}(11: \mathrm{n}=6,12: \mathrm{n}=9)$ and Boc- $\left[(R, R)-\mathrm{Ab}_{5,6} \mathrm{c}\right]_{6}$-OEt 13 in TFE solution $(50 \mu \mathrm{M})$. 
Molecular-mechanics calculation of hexapeptide Boc- $\left[(R, R)-\mathrm{Ab}_{5,6}=\mathrm{C}\right]_{6}-\mathrm{OEt}(11)$ :

Conformational search calculations were performed with the package of MacroModel ver. 8.1 (Schrodinger, Inc.) on SGI workstation. Monte Carlo Multiple Minimum (MCMM) method and AMBER* force field were used for finding the global minimum energy conformation and local ones. As initial structures, extended, 310 -helix and $\alpha$-helix structures were used. More than 50,000 conformers were optimized.

Hexapeptide (11):

PDB file name

a right-handed $(P) 3_{10}$-helix (0 kcal/mol, global minimum):

ANN-001P-01E.pdb

a left-handed $(M)$ 310-helix (+1.60 kcal/mol):

ANN-001M-01E.pdb 
Figure S6. Superimposition of the conformation determined by X-ray analysis (in red) and of the calculated (Macromodel) minimum-energy conformation (in green).

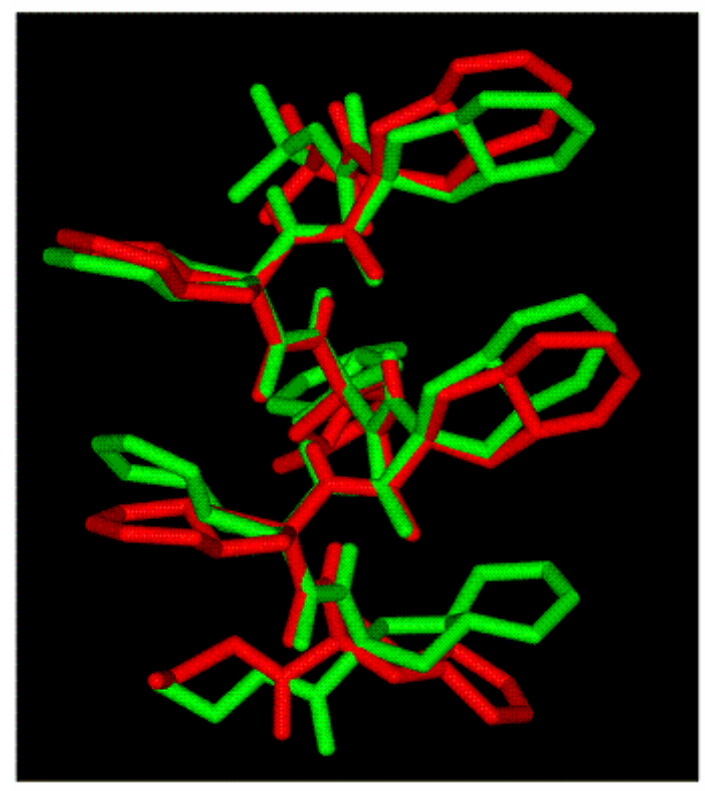

$A(P)+\mathrm{P} 001$

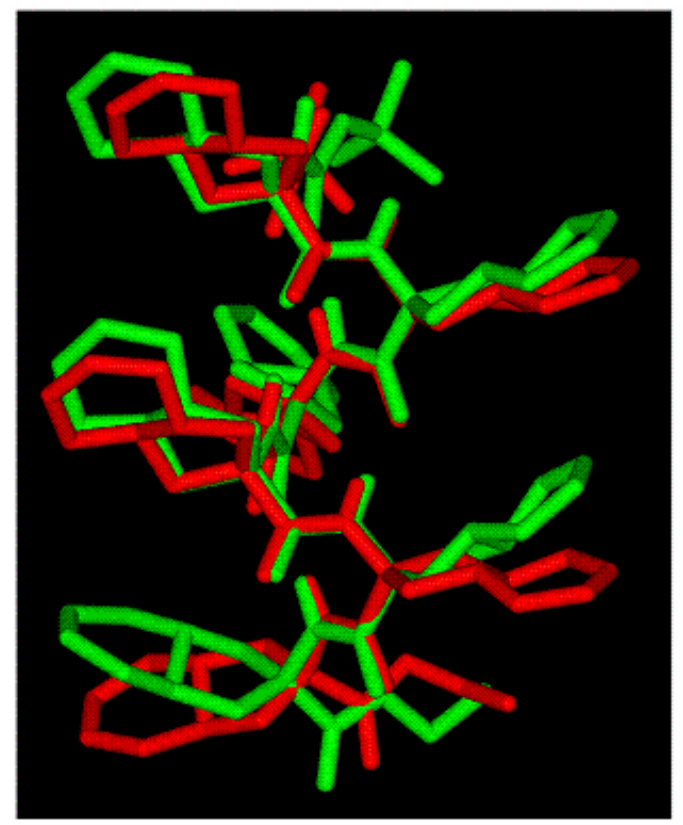

$B(M)+\mathrm{P} 001$

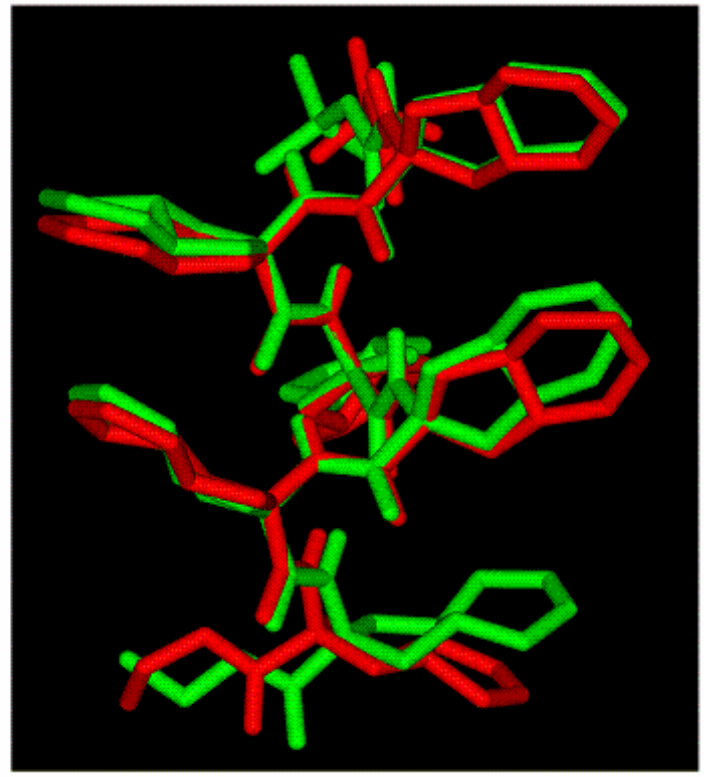

$D(P)+P 001$

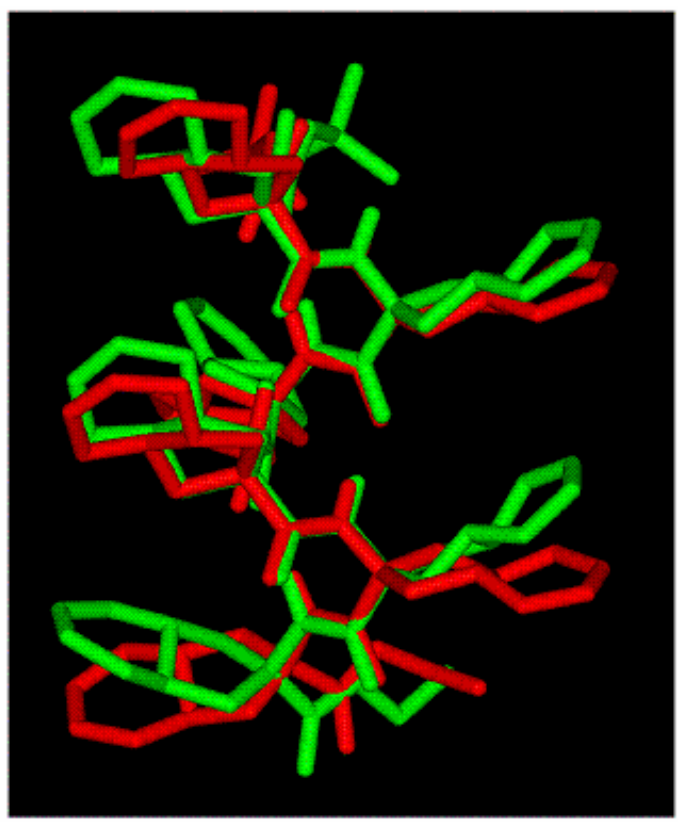

$C(M)+\mathrm{P} 001$ 
Table S1. Selected torsion angles $\left(^{\circ}\right)$ of hexapeptide $\mathbf{1 1}$ determined by the X-ray crystallographic analysis.

\begin{tabular}{crrrr}
\hline $\begin{array}{c}\text { Torsion } \\
\text { Angle }\end{array}$ & Molecule $A(P)$ & Molecule $B(M)$ & Molecule $C(M)$ & Molecule $D(P)$ \\
\hline$\omega_{0}$ & -176.1 & 172.7 & 172.5 & -171.8 \\
$\phi_{1}$ & -61.1 & 66.1 & 61.8 & -66.8 \\
$\psi_{1}$ & -25.2 & 19.0 & 26.7 & -19.9 \\
$\omega_{1}$ & -179.5 & 178.8 & 178.7 & 179.4 \\
$\phi_{2}$ & -60.9 & 59.1 & 56.8 & -59.1 \\
$\psi_{2}$ & -17.2 & 20.7 & 19.0 & -19.9 \\
$\omega_{2}$ & 176.0 & -178.3 & -178.8 & 174.9 \\
$\phi_{3}$ & -58.4 & 53.7 & 56.3 & -56.2 \\
$\psi_{3}$ & -20.6 & 29.4 & 23.6 & -24.8 \\
$\omega_{3}$ & 177.2 & 177.5 & -179.2 & 179.9 \\
$\phi_{4}$ & -59.9 & 59.2 & 54.1 & -59.8 \\
$\psi_{4}$ & -23.8 & 22.2 & 27.1 & -25.2 \\
$\omega_{4}$ & 175.4 & -178.7 & 179.2 & -179.0 \\
$\phi_{5}$ & -55.7 & 52.9 & 59.1 & -53.9 \\
$\psi_{5}$ & -32.7 & 37.5 & 27.4 & -37.7 \\
$\omega_{5}$ & -175.3 & 171.5 & 170.2 & -173.4 \\
$\phi_{6}$ & 51.2 & -48.4 & -54.6 & 48.6 \\
$\psi_{6}$ & 46.6 & -47.7 & -44.3 & 45.1 \\
$\omega_{6}$ & 157.9 & 179.4 & 179.6 & 179.8 \\
\hline
\end{tabular}

End. 